\title{
THE INFLUENCE OF ORGANIZATIONAL ACTIVITIES ON MEDICAL STUDENTS' ACADEMIC ACHIEVEMENT
}

\author{
Yolanda Ayu Yashinta*, Budi Utomo**, Fundhy Sinar Ikrar Prihatanto*** \\ * Fakultas Kedokteran, Universitas Airlangga, Surabaya - INDONESIA \\ ** Departemen Ilmu Kesehatan Masyarakat, Fakultas Kedokteran, Universitas Airlangga, \\ Surabaya - INDONESIA \\ *** Unit MERSDU, Fakultas Kedokteran, Universitas Airlangga, Surabaya - INDONESIA
}

\begin{abstract}
Background: The influence of extracurricular activities on academic achievement has been studied in several studies. Some studies support that extracurricular activities can negatively impact academic achievement but other studies emphasize the positive effects of extracurricular activities. Extracurricular activities discussed in this study is the activity of organizing students as measured by organizational activities and committees. The purpose of this study is to determine the effect of organizational activity measured by organizational activities and the committees that are followed by students on academic achievement.

Method: Cross-sectional study, using questionnaires distributed to 221 medical students class of 2014 in medical faculty of Airlangga University.

Results: This research was analyzed multivariate using $R$ program by using logistic regression test to know the influence of independent variable to dependent variable. From the results of this study found that the organizational activity measured from the student organization and committee activities have no significant effect on academic achievement.

Conclusion: organizational activities and committees play an important role in predicting the activity of organizing students, but from the results of this study found that the organizational activity measured from student organizations and committee activities have no significant effect on academic achievement.
\end{abstract}

Keywords: extracurricular activity, academic achievement, medical student

\section{PENGARUH KEAKTIFAN BERORGANISASI TERHADAP PRESTASI AKADEMIK MAHASISWA}

\begin{abstract}
ABSTRAK
Latar belakang: Pengaruh kegiatan ekstrakurikuler terhadap prestasi akademik telah diteliti dalam beberapa penelitian. Beberapa penelitian mendukung bahwa kegiatan ekstrakurikuler dapat berdampak negatif terhadap prestasi akademik namun penelitian lain menekankan efek positif dari kegiatan ekstrakurikuler. Kegiatan ekstrakurikuler yang dibahas dalam penelitian ini adalah keaktifan berorganisasi mahasiswa yang diukur dari kegiatan organisasi dan kepanitiaan. Tujuan dari penelitian ini adalah untuk mengetahui pengaruh keaktifan berorganisasi yang diukur dari kegiatan organisasi dan kepanitiaan yang diikuti oleh mahasiswa terhadap prestasi akademik.

Metode: Penelitian cross-sectional, dengan menggunakan kuesioner yang disebarkan ke 221 mahasiswa kedokteran angkatan 2014 di fakultas kedokteran Universitas Airlangga.

Hasil: Penelitian ini dianalisis secara multivariat menggunakan program $\mathrm{R}$ dengan menggunakan uji regresi logistik untuk mengetahui pengaruh variabel bebas terhadap variabel terikat. Dari hasil penelitian ini didapatkan bahwa keaktifan berorganisasi yang diukur dari organisasi mahasiswa dan kegiatan kepanitiaan tidak berpengaruh signifikan terhadap prestasi akademik.
\end{abstract}

Contact: yayuyashinta@gmail.com 
Kesimpulan: kegiatan organisasi dan kepanitiaan berperan penting dalam memprediksi keaktifan berorganisasi mahasiswa, namun dari hasil penelitian ini didapatkan bahwa keaktifan berorganisasi yang diukur dari organisasi mahasiswa dan kegiatan kepanitiaan tidak berpengaruh signifikan terhadap prestasi akademik.

Kata kunci: kegiatan ekstrakurikuler, prestasi akademik, mahasiswa kedokteran

\section{PENDAHULUAN}

Mahasiswa memiliki kegiatan yang cukup padat yaitu hadir di kuliah, mengikuti ujian, mengerjakan tugas perkuliahan, belajar, mengikuti kegiatan ekstrakurikuler, mengurus pekerjaan jika dia bekerja, berkumpul dengan keluarga, dan menjalani kehidupan sosial. Kegiatan mahasiswa yang cukup padat tersebut mengharuskan mahasiswa bisa mengelola komitmen, kemampuan belajar, mengalokasikan waktu dengan baik, karena banyaknya kegiatan tersebut dapat berpengaruh terhadap hasil akademik. ${ }^{1}$

Hasil akademik mahasiswa dapat dilihat dari Indeks Prestasi Kumulatif (IPK) mahasiswa. IPK adalah suatu indikator yang digunakan untuk mengukur prestasi akademik mahasiswa yang didapat dari jumlah angka mutu dibagi dengan jumlah Satuan Kredit Semester (SKS), angka indeks ini dimulai dari angka nol sampai dengan empat. ${ }^{2}$ Faktor-faktor yang dapat mempengaruhi Indeks Prestasi Kumulatif(IPK) adalah durasi tidur, ${ }^{3}$ durasi kegiatan ekstrakurikuler, ${ }^{4}$ jenis kelamin, ${ }^{5-7}$ kepatuhan beragama, ${ }^{8,9}$ etnis/ ras, ${ }^{10-12}$ latar belakang sosial-ekonomi, ${ }^{13-15}$ kegiatan ekstrakurikuler, ${ }^{16,17}$ dan peran orang tua. ${ }^{18-20}$

Mahasiswa kedokteran harus memiliki pengetahuan, keterampilan, dan sikap profesional, untuk itu pendidikan kedokteran menggunakan kurikulum, pengawasan dalam pembelajaran, mentoring, dan beberapa pengalaman untuk menambah wawasan mahasiswa, ${ }^{21}$ namun beberapa aspek lain kurang diperhatikan terutama mengenai kegiatan ekstrakurikuler di luar kelas.

Kegiatan ekstrakurikuler dalam hal ini organisasi kemahasiswaan adalah salah satu faktor yang menjadi peranan penting terhadap prestasi akademik. Hubungan antara kegiatan ekstrakurikuler dan prestasi akademik mahasiswa adalah topik terbuka yang dapat menjadikan suatu perdebatan. Beberapa penelitian mengungkapkan bahwa kegiatan ekstrakurikuler kampus dapat berdampak positif terhadap mahasiswa. Penelitian lain mengungkapkan efek negatif keterlibatan mahasiswa dalam kegiatan ekstrakurikuler. Pernyataan tersebut menunjukkan bahwa tidak semua kegiatan dapat bermanfaat bagi mahasiswa, dan manfaat dari keterlibatan mahasiswa bervariasi di seluruh kegiatan. ${ }^{22}$ Untuk itu, perlu diteliti lebih lanjut mengenai pengaruh kegiatan ekstrakurikuler khususnya organisasi kemahasiswaan yang diukur dari kegiatan organisasi dan kepanitiaan yang diikuti oleh mahasiswa terhadap prestasi akademik.

\section{METODE}

Penelitian ini merupakan jenis penelitian analitik observasional dengan desain penelitian cross sectional pada mahasiswa program studi S1 Pendidikan Dokter angkatan 2014 di Fakultas Kedokteran Universitas Airlangga. Penelitian cross sectional mencari hubungan antara keaktifan berorganisasi terhadap prestasi akademik.

Populasi dalam penelitian ini adalah 221 mahasiswa program studi S1 Pendidikan Dokter angkatan 2014 di Fakultas Kedokteran Universitas Airlangga dengan alasan untuk meningkatkan nilai validitas penelitian disamping masih terjangkau melaksanakan penelitian pada semua subjek.

Kriteria inklusi dalam penelitian ini adalah mahasiswa program studi S1 Pendidikan Dokter angkatan 2014 di Fakultas Kedokteran Universitas Airlangga. Kriteria eksklusi dalam penelitian ini adalah mahasiswa program studi S1 Pendidikan Dokter angkatan 2014 kelas internasional di Fakultas Kedokteran Universitas Airlangga. 
Variabel bebas penelitian ini adalah kegiatan kemahasiswaan yang terdiri dari organisasi kemahasiswaan dan kegiatan kepanitiaan. Variabel terikat penelitian ini adalah prestasi akademik

Teknik pengambilan data dalam penelitian ini adalah dengan menggunakan data primer dan data sekunder. Data primer pada penelitian ini menggunakan data hasil kuesioner. Data sekunder pada penelitian ini menggunakan data dari bagian Pendidikan Subprogram 1 Fakultas Kedokteran Universitas Airlangga untuk mengetahui nilai IPK mahasiswa program studi S1 Pendidikan Dokter angkatan 2014 reguler.

Data hasil penelitian dikumpulkan, disajikan dalam bentuk tabel, dinyatakan dalam rerata, dan standar deviasi kegiatan mahasiswa terhadap nilai IPK. Data dari hasil penelitian ini dianalisis secara multivariat menggunakan program $\mathrm{R}$ dengan menggunakan uji regresi logistik untuk mengetahui pengaruh variabel bebas terhadap variabel terikat. Variabel penelitian dapat dilihat pada tabel 1 .

Tabel 1 Definisi Operasional Variabel

\begin{tabular}{|c|c|c|c|}
\hline Variabel & Definisi Operasional & $\begin{array}{c}\text { Cara Pengukuran dan Hasil } \\
\text { Pengukuran }\end{array}$ & Skala Data \\
\hline $\begin{array}{l}\text { Organisasi } \\
\text { kemahasiswaan }\end{array}$ & $\begin{array}{l}\text { Organisasi } \\
\text { kemahasiswaan yang } \\
\text { dimaksud adalah jumlah } \\
\text { frekuensi pertemuan } \\
\text { organisasi yang diikuti } \\
\text { oleh mahasiswa dalam } 3 \\
\text { semester }\end{array}$ & $\begin{array}{l}\text { kuesioner: } \\
\text { Keaktifan organisasi = jumlah } \\
\text { organisasi x kegiatan dalam } \\
\text { organisasi x jumlah pertemuan } \\
\text { organisasi. }\end{array}$ & Rasio \\
\hline $\begin{array}{l}\text { Kegiatan } \\
\text { kepanitiaan }\end{array}$ & $\begin{array}{l}\text { Kegiatan kepanitiaan } \\
\text { yang dimaksud adalah } \\
\text { waktu yang dibutuhkan } \\
\text { oleh mahasiswa dalam } \\
\text { kegiatan kepanitiaan } \\
\text { dalam } 3 \text { semester }\end{array}$ & $\begin{array}{l}\text { Kuesioner: } \\
\text { Kepanitiaan = jumlah } \\
\text { kepanitiaan x jumlah } \\
\text { pertemuan } \mathrm{x} \text { durasi pertemuan } \\
\text { dalam kegiatan kepanitaan }\end{array}$ & Rasio \\
\hline Prestasi akademik & $\begin{array}{l}\text { Prestasi akademik } \\
\text { yang dimaksud adalah } \\
\text { nilai Indeks Prestasi } \\
\text { Kumulatif (IPK) yang } \\
\text { dimulai dari semester } 1 \\
\text { sampai dengan semester } \\
3\end{array}$ & $\begin{array}{l}\text { kuesioner: } \\
\text { nilai IPK dikategorikan sebagai } \\
\text { berikut: } \\
<2,75=0 \text { (rendah) } \\
2,75=1 \text { (tinggi) }\end{array}$ & Nominal \\
\hline Jenis kelamin & $\begin{array}{l}\text { Jenis kelamin mahasiswa } \\
\text { yang terdiri dari laki-laki } \\
\text { dan perempuan }\end{array}$ & $\begin{array}{l}\text { Laki-laki }=1 \\
\text { Perempuan }=2\end{array}$ & Nominal \\
\hline
\end{tabular}

\section{HASIL DAN PEMBAHASAN}

Penelitian yang dilakukan terhadap mahasiswa program studi S1 Pendidikan Dokter angkatan 2014 Fakultas Kedokteran Universitas Airlangga berdasarkan kriteria didapatkan 221 subjek yang terdiri dari 156 orang perempuan dan 65 orang lakilaki. Hasil penelitian dapat digambarkan pada tabel 2. 
Tabel 2. Distribusi Aktivitas Mahasiswa

\begin{tabular}{lccc} 
& IPK $<2,75$ & IPK $\geq 2,75$ & Nilai $\mathbf{p}$ \\
Organisasi & $6,00 \pm 6,23$ & $5,99 \pm 4,68$ & 0,99 \\
Kepanitiaan & $22,12 \pm 12,68$ & $23,78 \pm 17,82$ & 0,71 \\
Jenis Kelamin & & & 0,58 \\
$\quad$ Laki-laki & $6(9,2 \%)$ & $59(90,8 \%)$ & \\
$\quad$ Perempuan & $11(7,1 \%)$ & $145(92,9 \%)$ & \\
\hline
\end{tabular}

Keaktifan mahasiswa dari hasil penelitian didapatkan bahwa rata-rata mahasiswa dengan nilai IPK $<2,75$ lebih aktif mengikuti organisasi dibandingkan dengan mahasiswa yang memiliki nilai IPK $\geq 2,75$, namun tidak ada pengaruh yang signifikan antara keaktifan organisasi dengan prestasi akademik $(\mathrm{p}=$ 0,99).

Mahasiswa dengan nilai IPK $\geq 2,75$ rata-rata lebih aktif mengikuti kegiatan kepanitiaan dibandingan dengan mahasiswa yang memiliki nilai IPK $<2,75$, namun tidak ada pengaruh yang signifikan antara kegiatan kepanitiaan dengan prestasi akademik $(\mathrm{p}=$ $0,71)$.

\section{Indeks Prestasi Kumulatif sebagai Indikator Prestasi Akademik}

Indeks Prestasi Kumulatif (IPK) mahasiswa program studi S1 Pendidikan Dokter angkatan 2014 Fakultas Kedokteran Universitas Airlangga pada subprogram 1 didapatkan nilai IPK tertinggi yang diperoleh mahasiswa sebesar 3,91 dan nilai IPK terendah yang diperoleh mahasiswa sebesar 1,14.

\section{Pengaruh Keaktifan Berorganisasi terhadap Prestasi Akademik}

Keaktifan organisasi dari hasil penelitian didapatkan tidak ada pengaruh yang signifikan antara kegiatan organisasi dengan nilai IPK, begitu juga dengan kegiatan kepanitiaan yang juga tidak berpengaruh terhadap nilai IPK. Rata-rata mahasiswa dengan nilai IPK $<2,75$ lebih aktif mengikuti organisasi dibandingkan dengan mahasiswa yang memiliki nilai IPK $\geq 2,75$. Mahasiswa dengan nilai IPK $\geq 2,75$ rata-rata lebih aktif mengikuti kegiatan kepanitiaan dibandingan dengan mahasiswa yang memiliki nilai IPK $<2,75$.

Penelitian ini sejalan dengan penelitian Baker ${ }^{16}$ yang menyatakan bahwa tidak ada pengaruh signifikan antara organisasi terhadap prestasi akademik bagi kelompok ras dan gender manapun, namun dapat dilihat dari jenis aktivitas mahasiswa tersebut terlibat dapat mempengaruhi kinerja akademis.

Penelitian yang dilakukan oleh Lumley et $\mathrm{al}^{1}$ yang menyatakan bahwa kegiatan ekstrakurikuler berpengaruh positif terhadap prestasi akademik. Muller dan Ellison ${ }^{9}$ juga mengungkapkan keterlibatan remaja dalam organisasi keagamaan dapat berdampak positif terhadap hasil akademik, seperti kinerja akademik, harapan pendidikan, dan pencapaian pendidikan.

Perbedaan hasil penelitian antara peneliti dengan Lumley et $\mathrm{al}^{1}$ serta Muller dan Ellison ${ }^{9}$ disebabkan karena perbedaan faktor yang mempengaruhi sehingga antara penelitian yang satu dengan lainnya memberikan hasil yang berbeda-beda. Lumley et $\mathrm{al}^{1}$ menyatakan bahwa perbedaan mahasiswa dalam mengelola komitmen, keterampilan belajar, manajemen waktu juga dapat berpengaruh terhadap hasil akademis mereka.

Perbedaan jenis aktivitas organisasi yang diikuti mahasiswa juga dapat berpengaruh terhadap prestasi akademik. Baker ${ }^{16}$ menyatakan bahwa tidak semua aktivitas di dalam organisasi memberikan dukungan yang sama dalam prestasi akademik. Beberapa aktivitas dapat meningkatkan prestasi akademik, namun aktivitas yang lain dapat mengganggu prestasi akademik mahasiswa. 


\section{KESIMPULAN}

Keaktifan berorganisasi yang diukur dari organisasi mahasiswa dan kegiatan kepanitiaan tidak berpengaruh signifikan terhadap prestasi akademik.

\section{DEKLARASI KEPENTINGAN}

Artikel ini adalah bagian dari hasil karya tulis ilmiah pengarang pertama. Pengarang bertanggung jawab atas isi dan penulisan artikel ini. Adapun kontributor artikel ini adalah:

- Yolanda Ayu Yashinta adalah pengarang pertama yang melakukan penelitian sekaligus penulis naskah publikasi ini.

- Dr. Budi Utomo, dr., M.Kes adalah pembimbing 1 dalam perencanaan, pelaksanaan, penelitian, hingga pelaporan hasil penelitian serta penulisan naskah publikasi ini.

- Fundhy Sinar Ikrar Prihatanto, dr., M.Med. Ed adalah pembimbing 2 dalam perencanaan, pelaksanaan, penelitian, hingga pelaporan hasil penelitian serta penulisan naskah publikasi ini.

\section{DAFTAR PUSTAKA}

1. Lumley S, Ward P, Roberts L, Mann JP. Self-reported extracurricular activity, academic success, and quality of life in UK medical students. Int J of Med Ed. 2015;6:111-7.

2. Meuthia RF, Andriani W. Studi korelasi antara indek prestasi kumulatif (IPK) dengan nilai ujian komprehensif mahasiswa jurusan akuntansi Politeknik Negeri Padang. J R \& B. 2003;3(1):72-5.

3. Dewald JF, Meijer AM, Oort FJ, Kerkhof GA, Bogels SM. The influence of sleep quality, sleep duration and sleepiness on school performance in children and adolescents: a meta-analytic review. Sleep Med Rev. 2010;14(3):179-89.

4. La Torre G, Masala D, De Vito E, Langiano E, Capelli G, Ricciardi W. PHASES collaborative group. Extracurricular physical activity and socioeconomic status in italian adolescents. BMC Pub H. 2006;6(22):1-9.

5. Carvalho RGG. Gender differences in academic achievement: the mediating role of personality. Pers \& Ind Diff. 2016;94:54-8.

6. Voyer D, Voyer SD. Gender differences in scholastic achievement: a meta-analysis. Pshy Bull. 2014;140(4):1174-204.
7. Steinmayr R, Spinath B. Sex differences in school achievement : what are the roles of personality and achievement motivation? Eur J of Pers. 2008;22:185209.

8. Jeynes WH. The effects of religious commitment on the academic achievement of urban and other children. Edu \& Urb Soc. 2003;36(1):44-62.

9. Muller C, Ellison CG. Religious involvement, social capital, and adolescents' academic progress: evidence from the national education longitudinal study of 1988. Soc Foc. 2001;34(2):155-83.

10. Miller-Cotto D, Byrnes JP. Ethnic/racial identity and academic achievement: a meta-analytic review. Dev Rev [internet]; 2016 [cited 17 Juni 2016]. Available from http://linkinghub.elsevier.com/retrieve/pii/ S0273229716300338.

11. Rivas-Drake D, Umana-Taylor A, French S, Lee R, Syed M, Markstrom C, Schwartz SJ. Ethnic and racial Identity in the $21^{\text {st }}$ century. Feeling good, happy, and proud : a meta-analysis of positive ethnic-racial affect and adjustment. C Dev. 2014;85(1):77-102.

12. Byrd CM, Chavous TM. Racial identity and academic achievement in the neighborhood context: a multilevel analysis. J Y Adol. 2009;38:544-59.

13. Cheng S, Kaplowitz SA. Family economic status, cultural capital, and academic achievement: the case of taiwan. Int J of Edu Dev. 2016;49:271-8.

14. Kuh GD, Cruce TM, Shoup R, Kinzie J, Gonyea RM. Unmasking the effects of student engagement on first-year college grades and persistence. The J of High Ed. 2008;79(5):540-63.

15. Wu C. Higher education expansion and low-income students in taiwan. Int J of Edu Dev. 2009;29:399405.

16. Baker CN. Under-represented college students and extracurricular involvement: the effects of various student organizations on academic performance. Soc Psyc Ed. 2008;11:273-98.

17. Feldman AF, Matjasko JL. The role of school-based extracurricular activities in adolescent development: a comprehensive review and future directions. Rev of Edul Re. 2015;75(2):159-210.

18. Abar B, Carter KL, Winsler A. The effects of maternal parenting style and religious commitment on self-regulation, academic achievement, and risk behavior among african-american parochial college students. J of Ado. 2009;32(2):259-73. 
19. Topor DR, Keane SP, Shelton TL, Calkins SD. Parent Involvement and Student Academic Performance: A Multiple Mediational Analysis. J Prev Interv Com 2010;38(3):183-97.

20. Igbo JN, Sam OA, Onu VC, Dan M. Parent-child relationship motivation to learn and students academic achievement in mathematics. Int J of Re in App. 2015;3(9):87-108.
21. Liaison Comitte on Medical Education. Functions and Structure of a Medical School [Internet]; 2008 [cited 2016 june 6]. Available from https://umsc. org.uic.edu/documents/LCME_standards.pdf.

22. Correa M, Dumas BK, Jones C, Mbarika V, Ong' oa IM. Extracurricular activities and academic achievement: a literature review. Glob Adv Res J of Edu Res and Rev. 2015;4(9):165-9. 